Original Research Article

\title{
A study of treatment patterns in symptomatic management of fever in children (antipyresis) among Pediatricians
}

\author{
Benakanal S.V. ${ }^{1}$, Kumar V.S. ${ }^{2}$, Patil R.B. ${ }^{3}$ \\ ${ }^{1}$ Dr. Shreeshail V. Benakanal, Assistant Professor, Department of Paediatrics, Shivamogga Institute of Medical Sciences \\ Shivamogga, ${ }^{2}$ Dr. Vikram S. Kumar, Associate Professor; Department of Paediatrics, Subbaiah Institute of Medical Sciences, \\ Rajiv Gandhi University of Health Sciences, Bangalore, Karnataka, India, ${ }^{3}$ Dr. Ravindra B. Patil, Professor of Paediatrics, \\ Shivamogga Institute of Medical Sciences, Karnataka, India.
}

Corresponding Author: Dr. Vikram S. Kumar, Associate Professor; Department of Paediatrics, Subbaiah Institute of Medical Sciences, Shivamogga, Karnataka, India. E-mail: shreeben@gmail.com

\begin{abstract}
Background: Fever is an extremely common sign in pediatric patients and the most common cause for a child to be taken to the doctor. There are no guidelines or consensus in India about symptomatic management of fever and hence there can be too many misconceptions and conflicting results about fever management. Aims: In this study the aim was to identify knowledge gaps of primary care doctors regarding fever in children. Methods: This cross-sectional study was conducted from August 2019 -October 2019 involving Pediatricians and family physicians ( $\mathrm{n}=935)$. A questionnaire was administered to convenient samples of pediatricians and family physicians eliciting information about fever definition, methods of temperature measurement, and antipyretic use. Differences in responses between the doctors were evaluated. Results: The data was analyzed using the SPSS 16.0 program and descriptive statistics were used. In the present study $40 \%$ of the doctors knew that a body temperature of above $37.5^{\circ} \mathrm{C}$ according to an axillary measurement is defined as fever. Only $36 \%$ of the doctors took into consideration signs and symptoms other than fever to prescribe antipyretics. Almost $85 \%$ of the doctors prescribed antipyretics to control fever or prevent complications of fever especially febrile seizures. Most of the doctors (76.3\%) in this study reported that the intensity of fever may be used as an indicator for severe bacterial infection. A great majority of doctors $(65.3 \%)$ stated that they advised parents to alternate the use of ibuprofen and paracetamol. Conclusions: There were significant misconceptions about the management and complications of fever. There is a perceived need to improve the recognition, assessment, and management of fever with regards to underlying illnesses in children and a national consensus statement on fever and antipyresis in children.
\end{abstract}

Keywords: Antipyresis; Fever phobia; Pediatricians; India

\section{Introduction}

Fever is the most common cause for a child to be taken to the primary doctor, but the approach to the management of this sign varies significantly among pediatricians and primary care physicians [1]. Guidelines for symptomatic management of a febrile child have been published in many Western countries but the gap between available evidence and clinical practice seems still to be significant and poor adherence to the guideline recommendations has been reported. For a very longtime now, the beneficial effects of a febrile response have been known. [1,2,3,4] A few times, the health providers reinforce this fever phobia by their incomplete and insensible messages to parents. In a few studies, many primary care doctors and even Pediatricians believed that fever is dangerous and cause brain damage and febrile convulsions $[5,6,7,8]$.

Manuscript received: $4^{\text {th }}$ November 2019

Reviewed: $10^{\text {th }}$ November 2019

Author Corrected: $14^{\text {th }}$ November 2019

Accepted for Publication: $18^{\text {th }}$ November 2019
Although fever has beneficial effects and is good for the immune response, it seems that the negative perceptions of fever, like fears of febrile seizures and fever phobia, remain unchanged $[9,10]$. The health care providers continue to reduce low grade fever without other symptoms and recommend various kinds of antipyretics to feverish children. In brief, these misconceptions cause unnecessarily aggressive and inappropriate management of feverish children [7].

Nevertheless, there are also conflicting results about fever management in the literature and these conflicts may also contribute to doctors' misconceptions.

Hence, in the present study was aimed to identify the knowledge gaps and misconceptions of doctors regarding fever in children in our part of the world. 


\section{Subjects and Methods}

Settings and type of study- This cross-sectional study was conducted between august 2019-October 2019 involving doctors who had assembled during meetings, local CMEs and conferences in Karnataka State, India.

Sampling methods, Inclusion and exclusion criteriaAll subjects were interviewed by the use of a standardized self-administered questionnaire, designed on the bases of the recent United States and NICE (United Kingdom) guidelines for the management of fever in children $[1,3,4]$. Data was collected after the purpose of the study was explained to the participants and they were informed that their participation was voluntary. The study participants were all practicing doctors who worked in office and a few attached to a medical college during the period of study. All responses remained anonymous, and no identifier could be used to trace the participants on the survey. A sample was not selected, but there were attempts to contact the whole population. Fifteen of 950 Doctors refused (did not complete) participation (the participation rate was $98.4 \%$ ). The doctors were surveyed using a selfadministered questionnaire. It was comprised primarily of closed ended questions about basic knowledge, attitude and management of fever in children. No exclusion criteria was set.

Statistical methods- The data was analyzed using the SPSS 16.0 program and descriptive statistics were used.

\section{Results}

The study included 935 doctors (participation rate 98.4\%) with a mean age of $41.5 \pm 8.3$ and the male-female ratio was 2.3 . The socio-demographic characteristics of the participants are presented in Table 1. About $27.5 \%$ of the doctors indicated that they had read an article associated with fever in the last 6 months.

Table-1: Demographical characteristic of doctors.

\begin{tabular}{|l|c|}
\hline Characteristics & Descriptive statistics \\
\hline Total participants & 935 \\
\hline Male, N (\%) & $285(70 \%)$ \\
\hline Female, N (\%) & $46 \%)$ \\
\hline Age $($ Mean \pm SD) & 595 \\
\hline Paediatricians & 340 \\
\hline Family physicians & \\
\hline Marital status & $905(95 \%)$ \\
\hline Married N (\%) & $30(05 \%)$ \\
\hline Single N (\%) & \\
\hline Participant with children & $795(85 \%)$ \\
\hline Yes, N $\%)$ & $140(15 \%)$ \\
\hline No, N $(\%)$ & $10.8 \pm 1.8$ \\
\hline Duration of working per day (Mean \pm SD) & $257.4 \pm 68.1$ \\
\hline Number of patients per week (Mean \pm SD) & \\
\hline
\end{tabular}

Most of the doctors (83.8\%) recommended an axillary measurement of fever to the parents of the febrile child and $40 \%$ of them indicated that a body temperature of above $37.5^{\circ} \mathrm{C}$, according to an axillary measurement, was treated as fever. The body temperature treated as fever by doctors according to an axillary measurement varied between $36.5^{\circ} \mathrm{C}$ and $39^{\circ} \mathrm{C}$. About two third of doctors $(73.8 \%)$ reported that they recommended an antipyretic agent to every child under the age of 5 with fever. Only $26.2 \%$ of doctors took into consideration signs and symptoms other than fever (malaise, irritability, prolonged crying, signs of infection) to prescribe the antipyretic.

Nevertheless only $15 \%$ of doctors indicated that they prescribed antipyretics to ensure the child's comfort and remove irritability. The rest of the doctors prescribed antipyretics to control fever and prevent complications of fever, especially febrile seizures.

Some of the statements regarding the management and complications of fever, in agreement with these statements of doctors, are shown in Table 2. 
Original Research Article

Table-2: Knowledge of doctors regarding fever management and complications in febrile children under the age of 5 years.

\begin{tabular}{|c|c|c|c|}
\hline Statements & Yes $(\%)$ & No $(\%)$ & Not sure $(\%)$ \\
\hline Fever is dangerous & 33.6 & 66.4 & 0 \\
\hline $\begin{array}{l}\text { All fevers less than } 100^{\circ} \mathrm{F} \text { should be treated even when there are no } \\
\text { other signs and symptoms }\end{array}$ & 73.8 & 26.2 & 0 \\
\hline $\begin{array}{l}\text { All fevers of more than } 100^{\circ} \mathrm{F} \text { must definitely be treated whatever } \\
\text { is the underlying condition }\end{array}$ & 78.4 & 21.6 & 0 \\
\hline A febrile fit can be prevented by antipyretics & 88.7 & 1.8 & 9.5 \\
\hline Antipyretics should always be used in reducing fever & 90 & 8 & 2 \\
\hline $\begin{array}{l}\text { Other methods like tepid sponging and baths should be } \\
\text { recommended to reduce fever }\end{array}$ & 85 & 10 & 5 \\
\hline Cold water application can be used to reduce fever & 56 & 29 & 15 \\
\hline A child who is febrile and sleeping should not be disturbed & 35 & 60 & 5 \\
\hline When the fever increases the risk of febrile convulsion increases & 90 & 5 & 5 \\
\hline Febrile convulsion can cause brain damage & 30 & 68 & 2 \\
\hline $\begin{array}{l}\text { Paracetamol or ibuprofen usage can be used to prevent fever and } \\
\text { local reactions associated with childhood vaccination }\end{array}$ & 75 & 20 & 5 \\
\hline Paracetamol and Ibuprofen can be used alternatively & 71.3 & 23.7 & 5 \\
\hline Aspirin should not be used in a febrile child & 90 & 8 & 2 \\
\hline $\begin{array}{l}\text { Oral administration of paracetamol is better than rectal } \\
\text { administration in children }\end{array}$ & 72.3 & 24.7 & 3 \\
\hline $\begin{array}{l}\text { Paracetamol and ibuprofen are the only antipyretic drugs which } \\
\text { should be used in children. }\end{array}$ & 66.3 & 33.7 & 0 \\
\hline
\end{tabular}

A few doctors $(30 \%)$ indicated that febrile convulsions can cause brain damage. About $35 \%$ of the doctors said that fever is harmful for the child and $78.4 \%$ of them reported that a body temperature of above $38^{\circ} \mathrm{C}$ must definitely be treated, whatever the underlying pathology. Many $(89 \%)$ believed that the main reason for antipyretic usage is to prevent febrile convulsion and $85 \%$ indicated that physical methods (warm water bathing) should be recommended to reduce fever. Most of the doctors $(90 \%)$ believed there is a positive correlation between the height of fever and the incidence of febrile convulsion. Inappropriate beliefs about antipyretics were confirmed by the $78.7 \%$ who agreed that paracetamol and ibuprofen can be used alternatively. About $(66 \%)$ of the doctors agreed that only paracetamol and ibuprofen should be used as antipyretics in children.

\section{Discussion}

The study gave us an insight into the various misconceptions that existed among the health care providers. The first major finding of this research is a variation in the definition of fever. Fever is defined as a body temperature greater than $37.5^{\circ} \mathrm{C}$ according to an axillary measurement by primary care doctors and endorsed by the WHO and IMNCI [11]. In the present study only $40 \%$ of doctors knew that a body temperature of above $37.5^{\circ} \mathrm{C}$ according to an axillary measurement is defined as fever. Body temperature treated by doctors as fever varied between $36.5^{\circ} \mathrm{C}$ and $39.0^{\circ} \mathrm{C}$.

This range was too wide. Definitions of high fever by doctors also varied significantly in other studies [7-10]. In the present study most of the doctors $(83.8 \%)$ recommended an axillary measurement of fever to the families. There are conflicting results as regards this subject. Some authors consider tympanic measurement the best method for non-invasive measurement [10], some authors recommend an axillary measurement because it is easy to perform and generally well tolerated. However, it is not very sensitive $[11,12]$.

In the present study about two thirds of doctors recommended an antipyretic agent to every child under the age of 5 with fever, whatever the signs and symptoms. Only $26.2 \%$ of doctors took into consideration signs and symptoms other than fever (malaise, irritability, signs of infection) to prescribe an antipyretic. In fact, according to various guidelines, antipyretics should not be used 
Original Research Article

routinely in management of a febrile child. Use of antipyretics in children is recommended in case of prolonged crying, irritability, reduced activity and sleeplessness $[1,2,3,4,5]$. Only $15 \%$ of doctors indicated that they prescribed antipyretics to ensure a child's comfort and remove irritability, except for reducing fever. The rest of the doctors prescribed antipyretics to control fever and prevent complications of fever especially febrile seizures. International literature confirms that fever phobia is common among parents and health care workers.

Misconceptions about complications of fever especially febrile convulsions often push health care workers to over treat fever and this reinforces the phobia among parents $[13,14,15]$. The result of the present study confirmed these findings. According to the present study, the fever phobia continues. Almost 34\% considered fever to be dangerous for a child. It is known that antipyretic treatment has not been effective in the prevention of simple febrile seizures [12]. In the present study, $88.7 \%$ of doctors reported that the main reason for antipyretic usage was to prevent febrile seizure. The Studies conducted in other countries also endorse this ratio of $70 \%$, i.e. similar to that of the present study $[1,12]$.

Although there has been no evidence that fever causes brain damage unless it reaches above $41^{\circ} \mathrm{C}$, it is still a common misconception among doctors $[15,16]$. Fortunately, fever seen in children rarely reaches this high temperature. The most common side effects of fever are benign and include minimal dehydration, increased sleepiness, and discomfort. In the present study, $85 \%$ of doctors stated that fever was a risk factor for brain damage if it caused febrile seizure when uncontrolled. There are also other articles that surveyed primary care practitioners' opinions and behaviors with regards to fever, which confirm that fever is seen as a risk factor for brain damage. Unfortunately, health care providers and parents believe that brain damage is a consequence of fever $[16,17,18]$.

Febrile seizure is a rare complication of fever that occurs in $2-4 \%$ of febrile children and most are self-limited without any long-term sequelae $[16,17,18]$. Despite there being no evidence to suggest that brain damage may occur after febrile convulsion, in the present study $30 \%$ of the doctors believed that brain damage might occur after febrile convulsion. This misconception is common not only in the present study population but also among other health providers working in primary health care, hospitals and emergency rooms.

In the present study, $85 \%$ of doctors agreed that the higher the temperature, the higher the likelihood of a febrile seizure. There are conflicting results about the association between the risk of febrile convulsion and the height of fever. Many studies have shown that, almost one third of all children who have febrile seizures will have a second episode despite attempts to prevent fever with antipyretics and there was no evidence found that antipyretic treatment reduced the risk of febrile convulsions [6].

Most of the doctors $(76.3 \%)$ in this study reported that height of fever can be used as an indicator for severe bacterial infection. According to evidence obtained from observational studies height of fever should not be taken as an indicator of the severity of the underlying pathology by itself. In children of less than 3 months of age, height of fever may be an indicator of severe bacterial infection [19].

In the present study, only $10 \%$ of participants agreed that a sleeping febrile child should not be disturbed. There are studies which show that parents, doctors and nurses awaken sleeping febrile children who have no other symptoms for antipyretic administration. Accordingly, sleeping febrile child need not be awakened for any reason, including medication $[8,17,18]$.

In various fever management guidelines and studies of the use of these methods to reduce fever, physical methods are not recommended as their usage may be associated with adverse effects and a paradoxical increase in fever and cause more discomfort to the child [19,20,21].

More than half of participating doctors (66.3\%) agreed that paracetamol and ibuprofen are the only antipyretic drugs which should be used in children. Studies show that both drugs are more effective than placebo, and can be used confidently in children [22,23]. Evidence obtained from randomized controlled clinical trials show that paracetamol and ibuprofen are the only antipyretic drugs recommended for use in children. Inspite of this, in the present study, nearly $35 \%$ of doctors were using Mefenemic acid, Nimesulide and other combination drugs for antipyresis.

Most of the doctors who participated in the present study (91.3\%) reported that Acetylsalicylic acid should not be used in a febrile child, although this has been known for a long time, nearly $10 \%$ of doctors were unsure.

In this study $72.3 \%$ of doctors preferred oral administration to rectal administration. Some investigations show that oral acetaminophen is more effective than the rectal form [24].; others found they had similar effects [25] so the comparison of the antipyretic effects of rectal and oral acetaminophen has conflicting results. Use of rectal paracetamol is not recommended by many guidelines because of the risk of overdose. It is difficult to achieve precise dosage in rectal administration. 
Original Research Article

There are conflicting results about fever management in the literature and this situation could affect the practices of doctors. In many articles alternative treatments of fever with paracetamol and ibuprofen are recommended [26,27,28,29] and alternating acetaminophen and ibuprofen in febrile children appears to be a common practice among doctors. But according to guidelines about management of fever in children; combined or alternating the usage of ibuprofen and paracetamol is not recommended. There is no evidence available that alternating therapy results in improvement in other clinical outcomes and there is also no evidence regarding the safety of this practice. In the present study a great majority of doctors $(71.3 \%)$ stated that they advised parents to alternate the use of ibuprofen and paracetamol.

Preventive usage of antipyretic before vaccine application is a common implementation in primary health care in India despite the absence of evidence. Most of the doctors $(75 \%)$ in the present study reported that antipyretic usage should be recommended to prevent fever and local reaction associated with childhood vaccination. According to evidence obtained from well-designed randomized clinical trials, use of paracetamol or ibuprofen is not recommended to reduce fever and local reactions associated with vaccination $[30,31]$.

The present investigation may have potential limitations. Our results may not generalize to all primary health care providers. The present study does not provide information regarding possible differences in responses according to the geographical distribution and age. It is well known that self-reported behaviors can be misleading since some participants might not complete the survey as carefully as they would act in real settings.

Our data suggests that implementation of educational programs and using guidelines regarding the proper management of the febrile child are needed. There were misconceptions about management and complications of fever. Conflicting results about fever in the literature also reinforces these misconceptions.

Although there are guidelines for many diseases in primary care, there is no national guidance on the symptomatic management of fever in India. The management of fever varies across India and also among doctors. As a result, there is a perceived need to improve the recognition, assessment, and management of fever with underlying illnesses in children.

\section{Conclusions}

There were significant misconceptions about the management and complications of fever. There is a perceived need to improve the recognition, assessment, and management of fever with regards to underlying illnesses in children and a national consensus statement on fever and antipyresis in children.

\section{What this study adds to the existing knowledge?}

There is a perceived need to improve the recognition, assessment, and management of fever with underlying illnesses in children.

\section{Author's contribution}

Dr. Shreeshail V. Benakanal, Dr. Vikram S. Kumar, were primary investigators for the study, collection of proforma, questionnaires, and interpretation of the study. Dr. R B Patil was the senior adviser for the study.

Funding: No funding sources

Conflict of interest: None declared

Ethical Approval: This study was approved by the Institutional Ethics Committee

\section{Reference}

1. Davis T. NICE guideline: feverish illness in childrenassessment and initial management in children younger than 5 years. Arch Dis Child Educ Pract Ed. 2013;98:232235. doi:10.1136/archdischild-2013-304792.

2. Chiappini E, Principi N, Longhi R, Tovo PA, Becherucci P, Bonsignori $\mathrm{F}$ et al: Writing Committee of the Italian Pediatric Society Panel for the Management of Fever in Children. Management of fever in children: summary of the Italian Pediatric Society guidelines. Clin Ther. 2009; 31(8): 1826-1843. doi: 10.1016/j. clinthera. 2009. 08.006.

3. Bilenko N, Tessler H, Okbe R, Press J, Gorodischer R. Determinants of antipyretic misuse in children up to 5 years of age: a cross-sectional study. Clin Ther. 2006; 28(5): 783-793. doi: https://doi.org/10.1016/j.clinthera. 2006. 05.010 .

4. Richardson M, Lakhanpaul M. Guideline Development Group and the Technical Team: Assessment of initial management of feverish illness in children younger than 5 years: summary of NICE guidance. BMJ. 2007; 334 (7604) : 1163-1164. doi: 10.1136/bmj. 39218. 495255. AE.

5. Demir F, Sekreter O, Knowledge, attitudes and misconceptions of primary care physicians regarding fever in children: a cross sectional study. Ital J Pediatr. 2012; 38: 40. doi: 10.1186/1824-7288-38-40. 
Original Research Article

6. Flores G, Lee M, Bauchner H, Kastner B: Pediatricians' attitudes, beliefs, and practices regarding clinical practice guidelines: a national survey. Pediatr. 2000;105(3 pt 1): 496-501. doi: 10.1542/peds.105.3.496.

7. Crocetti M, Moghbeli N, Serwint J: Fever phobia revisited: have parental misconceptions about fever changed in 20 years? Pediatr. 2001;107(6):1241-1246. doi: https:// doi.org/10.1542/peds.107.6.1241.

8. Lava SA, Simonetti GD, Ferrarini A, Ramelli GP, Bianchetti MG: Regional differences in symptomatic fever management among paediatricians in Switzerland: the results of a cross-sectional web-based survey. Br J Clin Pharmacol. 2013; 75(1):236-243. doi: 10.1111/j.13652125. 2012. 04311.x.

9. Lava SA, Simonetti GD, Ramelli GP, Tschumi S, Bianchetti MG: Symptomatic management of fever by Swiss board-certified pediatricians: results from a crosssectional, Web-based survey. Clin Ther. 2012;34(1):250256.doi: 10.1016/j.clinthera.2011.12.002. Epub 2012 Jan 2

10. Melamud A, Suwezda A, Matamoros R, Ringuelet L: Antipyretics indication by pediatricians: internet as a tool in data collections. Arch Argent Pediatr. 2008;106(5):404408. doi: 10.1590/S0325-00752008000500006.

11. Eichenwald HF: Fever and antipyresis. Bull World Health Organ. 2003;81(5):372-374.

12. Chiappini E, D’Elios S, Mazzantini R, Becherucci P, Pierattelli M, Galli L, et al.: Adherence among Italian paediatricians to the Italian guidelines for the management of fever in children: a cross sectional survey. BMC Pediatr. 2013;13(1):210. doi: 10.1186/1471-2431-13-210.

13. Sullivan JE, Farrar HC: Section on Clinical Pharmacology and Therapeutics Committee on Drugs. Fever and antipyretic use in children. Pediatr. 2011; 127(3):580-587. doi: 10.1542/peds.2010-3852. Epub 2011 Feb 28.

14. Bilenko N, Tessler H, Okbe R, Press J, Gorodischer R. Determinants of antipyretic misuse in children up to 5 years of age: a cross-sectional study. Clin Ther. 2006; 28 (5): 783-793. doi: https://doi.org/10.1016/j.clinthera. 2006. 05.010 .

15. Seow VK, Lin AC, Lin IY, Chen CC, Chen KC, Wang $\mathrm{TL}$, et al. Comparing different patterns for managing febrile children in the ED between emergency and paediatric physicians: impact on patient outcome. Am J Emerg Med. 2007;25(9):1004-1008. doi: https://doi.org /10. 1016/j.ajem.2007.03.001.
16. Sillanpa M, Suominen S, Rautava P, Aromaa M: Academic and social success in adolescents with previous febrile seizures. Seizure. 2011;20(4):326-330. doi: 10. 1016/j. seizure.2010.12.019.

17. Walsh, Anne M. Available evidence does not support routine administration of antipyretics to reduce duration of fever or illness. Evid Based Nurs. 2011;14(2):58-59. doi: 10. 1136/ebn.14.2.58.

18.Offringa M, Newton R: Prophylactic drug management for febrile seizures in children. Cochrane Database Syst Rev. 2012;(4):CD003031. doi: 10.1002/ 14651858. CD 003031. pub2.

19. Trautner BW, Caviness AC, Gerlacher GR, Demmler G, Macias CG: Prospective evaluation of the risk of serious bacterial infection in children who present to the emergency department with hyperpyrexia (temperature of $106^{\circ} \mathrm{F}$ or higher). Pediatr. 2006;118(1):34-40. doi: https:// doi.org/ 10.1542/peds.2005-2823.

20. Meremikwu M, Oyo-Ita A: Physical methods for treating fever in children. Cochrane Database Syst Rev 2003;2(2):CD004264. doi: 10.1002/14651858.CD004264.

21. Thomas S, Vijaykumar C, Naik R, Moses PD, Antonisamy B. Comparative effectiveness of tepid sponging and antipyretic drug versus only antipyretic drug in the management of fever among children: A Randomized Controlled Trial. Indian Pediatr. 2009;46(2): 133-136.

22. Perrott DA, Piira T, Goodenough B, Champion GD: Efficacy and safety of acetaminophen vs ibuprofen for treating children's pain or fever: a meta-analysis. Arch Pediatr Adolesc Med. 2004;158(6):521-526. doi:10.1001/ archpedi.158.6.521.

23. Edward Purssell. Systematic review of studies comparing combined treatment with paracetamol and ibuprofen, with either drug alone. Arch Dis Child. 2011;96: 1175-1179. doi:10.1136/ archdischild-2011300424.

24. Scolnik D, Kozer E, Jacobson S, Diamond S, Young NL: Comparison of oral versus normal and high-dose rectal acetaminophen in the treatment of febrile children. Pediatr. 2002;110(3):553-556. DOI: https://doi.org/10. 1542 / peds. 110.3 .553 .

25. Nabulsi M, Tamim H, Sabra R, Mahfoud Z, Malaeb S, Fakih H, Mikati M: Equal antipyretic effectivness of oral and rectal acetaminophen: a randomized controlled trial. BMC Pediatr ,2005;5(35). doi:10.1186/1471-2431-5-35. 
Original Research Article

26. Lal A, Gomber S, Talukdar B. Antipyretic effects of nimesulide, paracetamol and ibuprofen-paracetamol. Indian J Pediatr. 2000;67(12):865-870.

27. Wong $\mathrm{T}$, Stang AS, Ganshorn H, Hartling L, Maconochie IK, Thomsen AM et al. Combined and alternating paracetamol and ibuprofen therapy for febrile children (Review). Coch Data System Rev. 2013;10: CD009572. doi: 10.1002/14651858.CD009572.pub2.

28. Hay AD, Costelloe C, Redmond NM, Montgomery AA, Fletcher M, Hollinghurst S, et al. Paracetamol plus ibuprofen for the treatment of fever in children (PITCH): randomized controlled trial. BMJ 2008;337:a1302. doi: 10.1136/bmj.a1302.

29. Wright AD, Liebelt EL: Alternating antipyretics for fever reduction in children: an unfounded practice passed down to parents from pediatricians. Clinic Pediatr (Phila). 2007; 46 (2):146-150. doi: https://doi.org/10.1177/00099 22806293922.

30. PrymulaR, Siegrist CA, Chlibek R, Zemlickova H, Vackova M, Smetana J, et al. Effect of prophylactic paracetamol administration at time of vaccination on febrile reactions and antibody responses in children: two openlabel, randomised controlled trials. Lancet 2009;374 (9698): 1339-1350. doi: 10. 1016/ S0140-6736 (09) 61208-3.

31. Jackson LA, Dunstan M, Starkovich P, Dunn J, Yu O, Nelson JC, et al. Prophylaxis with acetaminophen or ibuprofen for prevention of local reactions to the fifth diphtheria-tetanus toxoids acellular pertussis vaccination: a randomized, controlled trial. Pediatr. 2006; 117(3): 620625. doi: https://doi.org/10.1542/peds.2005-1217.

\section{How to cite this article?}

Benakanal S.V, Kumar V.S, Patil R.B. A study of treatment patterns in symptomatic management of fever in children (antipyresis) among Pediatricians. Int J Pediatr Res.2019;6(12): 589-595.doi:10.17511/ijpr.2019.i12.01 